\title{
UMA VISÃO SOBRE OS MUSEUS DE CIÊNCIAS COMO ESPAÇOS NÃO FORMAIS: O BOSQUE DA CIÊNCIA UM EXEMPLO AMAZỔNICO
}

\author{
A VISION ABOUT SCIENCE MUSEUMS AS NON-FORMAL SCENERY: THE \\ SCIENCE FOREST AN AMAZONIC EXAMPLE
}

Saulo Cézar Seiffert Santos ${ }^{1}$

ORCID iD: $\underline{0000-0001-7890-1886}$

\begin{abstract}
RESUMO
Espaços não formais, como Museus de Ciências, têm contribuído com a sociedade, e mais especificamente com a escola, para a popularização da Ciência e, assim, somando à formação cidadã. Na região Norte do Brasil, a Amazônia, há poucos museus, mas há diversos espaços abertos não formais que assumem essa função. A partir desse quadro problematizamos e propomos possíveis relações entre os Museus de Ciências, a Divulgação Científica e a Escola, na condição de esferas de atividades relativamente autônomas, e em seguida nos ateremos aos possíveis dialogismos do Museu de Ciências com a Escola a partir das pesquisas com o Bosque da Ciência, do Instituto Nacional de Pesquisa da Amazônia. Utilizamos a estratégia do ensaio acadêmico para construir esse diálogo. Consideramos que as relações dessas três esferas produzem formas próprias de promover a formação e a divulgação científica, e que nas interações entre escola e museu se faz necessário superar as abordagens fechadas e monológicas, além de se abrir para interações, não somente de recursos, mas também de propostas dialógicas de educação para a formação que promova a cultura científica e cidadã.
\end{abstract}

Palavras-chave: Museu de Ciências. Escola. Educação não formal. Divulgação Científica. Amazônia.

\begin{abstract}
Non-formal places such as Science Museums have contributed to society, and more specifically to the school for the popularization of Science, and thus adding to the citizen formation. In the North region of Brazil, the Amazon, there are few museums, but there are several open non-formal spaces that assume this function of museum. Thus, we problematize and propose possible relations between the Science Museums, Scientific Dissemination and School, as spheres of relatively autonomous activities, and then we will stick to the possible dialogues between the Science Museum and the School based on research with the Science Forest of the National Institute of Science. Amazon Research. We believe that the relationships of these three spheres produce their own ways of promoting scientific education and popularization, and in the interactions between school and museum, it is necessary to overcome closed and say monological approaches, but to open up to interactions not only with resources, but with dialogic educational proposals for training that promotes scientific and citizen culture.
\end{abstract}

Keywords: Science Museum. School. Non-formal education. Scientific popularization. Amazon.

\footnotetext{
${ }^{1}$ Doutor em Educação em Ciências pela Universidade Estadual do Oeste do Paraná (Unioeste). Professor Adjunto do Instituto de Ciências Biológicas da Universidade Federal do Amazonas (UFAM), Manaus, Amazonas, Brasil. Endereço para correspondência: Av. Gen. Rodrigo Octávio, 6200, Setor Sul, Prédio ICB 01, Departamento de Biologia, Coroado I, Manaus, Amazonas, Brasil, CEP: 69080-900. E-mail: sauloseiffert@ufam.edu.br.
} 


\section{INTRODUÇÃO}

A Divulgação Científica (DC) é fruto da pesquisa e da construção cultural e institucional da sociedade em um momento histórico e geograficamente situado. Por exemplo, vemos no momento histórico muitos materiais em mídias de gêneros diversos, outrora em livros de fícção científica, hoje em vídeos e na internet, livros didáticos, revistas de popularização da ciência, tecnologia e cultura (nas formas impressas e digitais), museus de ciências e parques temáticos.

Por parte geográfica, frisamos a região Norte, compreendida, na sua maior parte, pela Amazônia Brasileira, que é o locus da maior floresta tropical do mundo - a chamada floresta amazônica do bioma amazônico - e ocupa grande parte do território nacional. Não obstante, há elementos que indicam que a região é pouco conhecida e pouco estudada, apesar de muitos esforços nacionais e internacionais nesse sentido (FONSECA, 2011). Esse pouco conhecimento pode ser comprovado, por exemplo, pelo indicador do número de instituições dedicadas à produção científica, pois outras regiões do país apresentam um número muito maior de instituições dedicadas ao campo da Ciência e Tecnologia (ABCMC, 2015).

Citamos o Amazonas, estado que sequer possui um museu de Ciências público (COSTA, 2011), embora existam zoológicos e parques ambientais. Esse quadro infelizmente indica que a DC é parcamente apresentada a partir da realidade regional ou local. Na situação do Amazonas, como é o caso também de outros estados da região Norte, há parques, jardins, aquários e ambientes onde o "vivo" é o destaque. Dessa forma, a região Norte apresenta uma característica diferenciada em relação aos demais estados da federação, em especial no que se refere à divulgação da Ciência feita em poucos espaços não formais de educação, o que pode acarretar uma dificuldade da população para buscar e ter acesso a uma cultura científica mais ampla.

Diante desse panorama, apresentamos alguns exemplos de pesquisa para este estudo a partir do Espaço de Ciência e Tecnologia - ECT amazônico, visando a divulgação de pesquisas de locus amazônico, o Bosque da Ciência², administrado pelo Instituto Nacional de Pesquisa

\footnotetext{
${ }^{2}$ O Bosque da Ciência foi criado em 1995, com um espaço físico de 13 hectares, localizado na Zona Centro-Leste de Manaus/AM, destacando-o como espaço socioeducativo para promoção da divulgação científica e educação ambiental para visitantes da comunidade e das escolas relacionadas às pesquisas do INPA. A instituição informa em seu site que seus objetivos são: desenvolver e promover o programa do INPA para difusão tecnológica, científica e de inovação; oferecer à população local uma opção de lazer que possa contribuir para sua educação cultural e ambiental (SEIFFERT-SANTOS; CUNHA, 2018).
} 
da Amazônia - INPA, Manaus/AM. Também apresentamos outras pesquisas nacionais e internacionais no decorrer do estudo.

O nosso objetivo é propor de forma ensaística e inicial possíveis relações investigativas científicas pedagógicas no encontro entre a escola (educação formal), o museu de ciências (educação não formal) e a divulgação científica; e depois, ilustrar, por meio da relação escola/museu de ciências, um exemplo amazônico para analisar o desdobramento do dialogismo de uma das relações de investigação científica pedagógica, valendo-nos de trabalhos publicados sobre o Bosque da Ciência/INPA (um ambiente de recepção de visitas escolares).

\title{
2 PROCEDIMENTO METODOLÓGICO: UM ENSAIO PARA QUÊ?
}

\author{
Segundo Meneghetti (2011, p. 323)
}

O ensaio [teórico] é um meio de análise e elucubrações em relação ao objeto, independentemente de sua natureza ou característica. A forma ensaística é a forma como são incubados novos conhecimentos, até mesmo científicos ou pré-científicos.

O ensaio acadêmico não é do mesmo gênero textual do artigo científico (CAMPUS, 2015), pois defende uma posição argumentativa e subjetiva para indicar novas formas de ver temas e problemas sem ser exaustivo na pesquisa bibliográfica (FERRI, 2011). Logo, o ensaio propõe uma reflexão teórica que não se confunde com uma revisão, seja uma revisão narrativa, integrativa ou sistemática (MATTOS, 2015).

Com base em Adorno, Meneghetti (2011) defende que o ensaio é uma expressão digna de "dançar" com a diversidade de elementos da pesquisa (acompanhando), sem se prender demasiadamente, podendo, assim, ter liberdade para criticar e dar mérito aos feitos realizados. Resumidamente, para Ferri (2011) o ensaio acadêmico se caracteriza por trazer a atualidade do tema, sem ter uma estrutura rígida, além de trazer uma forma de pensar pessoal, dialogando com o tema, que é tratado de forma específica em um momento histórico.

Dessa forma, como expressamos acerca da Amazônia na introdução, o fato de existirem poucas instituições científicas e a característica do vivo e do ambiente aberto ser presente in loco nos fizeram questionar sobre as formas de pesquisa no que denominamos em um quadro amplo como espaços não formais, uma vez que é sabido que não há um consenso na literatura internacional e nacional sobre a tipologia desses desenhos educativos e suas nomenclaturas (MARANDINO, 2017). À vista disso, vemos como mais apropriado a essa temática o uso da estratégia ensaística para dialogar com novas ideias. Portanto, empregamos o modo ensaístico 
partindo de uma tese teórica e fazemos um diálogo com autores no âmbito internacional, nacional e regional para sua viabilidade racional argumentativa.

Para este ensaio escolhemos e pensamos as esferas da atividade humana, a Escola, o Museu de Ciências e a Divulgação Científica - destacadas de várias outras esferas do fenômeno educativo - e as possíveis relações na interseção dessas esferas na atividade da investigação científica. Nesse contexto mais amplo separamos a relação Escola/Museu de Ciências para analisar possíveis interações e dialogismos do processo educativo.

Assim, defendemos que a divulgação científica se dá por meio de relações de construção de sentido na circulação das esferas da atividade humana, no qual se destacam a Escola e o Museu de Ciências, por seus projetos educativos, observado que suas interações dialógicas podem ser valoradas de forma positiva elou negativa para possibilitar uma formação dialógica ou monológica dos públicos.

Nesse sentido, selecionamos uma instituição importante para a Divulgação Científica no Estado do Amazonas, pertencente a uma Instituição de Ciência e Tecnologia, a saber, o Bosque da Ciência do INPA. O espaço se identifica na nossa tipologia como Museu de Ciências que promove a popularização da ciência junto à Escola e, a partir disso, analisamos as formas de interações percebidas, ou ausentes, na pesquisa entre ambas.

\section{CAMPOS DA DIFUSÃO DA CIÊNCIA E TECNOLOGIA ${ }^{3}$}

Podemos entender que os conteúdos científicos e tecnológicos têm sido ofertados tanto por agências e instituições diversas, mormente ligadas à formação/educação formal/escolar, embora também, em menor escala, à educação não formal, quanto por museus de Ciências e similares (MARANDINO, 2001; VALENTE et al., 2005), e também por meio de mídias diversas de divulgação científica construídas e publicadas por editoras e produtores independentes (SEIFFERT-SANTOS, 2016; CAZELLI; VALENTE, 2019).

Esse tipo de pesquisa que relaciona a Escola com os museus de Ciências (ou a Divulgação Científica) normalmente transita na busca de construção ou delimitação em relação aos epítetos formal, não formal e informal (MARANDINO, 2011; SEIFFERT-SANTOS; FACHÍN-TERÁN, 2013; OVIGLI, 2015). Contudo, não são definições eficientes, e deixam a

\footnotetext{
${ }^{3}$ Esta seção possui partes reformuladas do relatório de tese do meu curso de doutorado com o título "O discurso expositivo de um espaço amazônico de educação não formal em Ciência e Tecnologia: o caso do Bosque da Ciência" sob orientação da Profa. Dra. Márcia Borin da Cunha, desenvolvida no PPGECEM/Unioeste.
} 
fugir características híbridas e de contexto cultural, ou seja, frequentemente deixa de fazer jus à realidade (MARANDINO, 2017).

Nesse contexto, a escola é indicada como responsável pelo letramento científico ${ }^{4} \mathrm{em}$ nível de competências, conhecimentos e valores nos âmbitos da Educação Básica e da Educação Superior (NRC, 2009; STOCKLMAYER et al., 2010).

Subsidiariamente, a Divulgação Científica (DC) é vista como responsável pela disponibilização da informação científica e tecnológica ao público amplo, escolar e não escolar, no formato do jornalismo científico e no formato de popularização da Ciência para a formação cidadã e crítica (BUENO, 2002; NASCIMENTO, 2010).

Das formas de divulgação científica, o Museu de Ciências e seus similares (zoológicos, jardins botânicos, parques e outros) são instituições ou ECT com função de popularização dessas produções da cultura científica como modalidade própria e características distintas (CGEE, 2019). São ao mesmo tempo, contudo, instituições de recepção de visitas que normalmente apresentam o seu projeto de educação não formal (museal) próprio (MARANDINO, 2001; ESHACH, 2007; PALHARES, 2009).

Os museus de Ciências são considerados como um tipo de educação não formal (CHAGAS, 1993). A recente atualização da definição de museu, segundo o Conselho Internacional de Museus (International Council of Museums - ICOM), apresenta:

Os museus são espaços democratizantes, inclusivos e polifônicos para um diálogo crítico sobre o passado e o futuro. Reconhecendo e abordando os conflitos e desafios do presente, eles mantêm artefatos e espécimes em confiança para a sociedade, salvaguardam diversas memórias para as gerações futuras e garantem direitos iguais e acesso igual ao patrimônio para todas as pessoas. Os museus não são lucrativos. Eles são participativos e transparentes, e trabalham em parceria ativa com e para diversas comunidades para coletar, preservar, pesquisar, interpretar, exibir e melhorar a compreensão do mundo, visando contribuir para a dignidade humana e justiça social, igualdade global e bem-estar planetário. (Tradução livre). ${ }^{5}$ (ICOM, 2019, online).

\footnotetext{
${ }^{4}$ No trabalho citado está como scientific literacy, que pode ser traduzido como alfabetização científica ou letramento científico. No nosso trabalho adotamos a tradução letramento científico para contribuir com o sentido de que o aluno é iniciado a ler a realidade do ponto de vista da Ciência e Tecnologia, e assim podendo ser um praticante no seu grupo de práticas culturais (CUNHA, 2017).

${ }^{5}$ Museums are democratizing, inclusive and polyphonic spaces for critical dialogue about the pasts and the futures. Acknowledging and addressing the conflicts and challenges of the present, they hold artefacts and specimens in trust for society, safeguard diverse memories for future generations and guarantee equal rights and equal access to heritage for all people. Museums are not for profit. They are participatory and transparent, and work in active partnership with and for diverse communities to collect, preserve, research, interpret, exhibit, and enhance understandings of the world, aiming to contribute to human dignity and social justice, global equality and planetary well-being. ICOM. Definição de Museu. Disponível em:
} https://icom.museum/en/activities/standards-guidelines/museum-definition/?fbclid=IwAR2OIpsWyJLfce 1Bej1H1otK9a06e5i358gTaX36rjmRyty31PbIeclapZc. Acessado em 06 ago. 2019. 
Outra forma de definir o museu é pela Portaria n ${ }^{\circ} .422 / 2017$, do Ministério da Cultura, por meio do Instituto Brasileiro de Museus, que dispõe sobre a Política Nacional de Educação Museal, fundamentando-se no artigo $2^{\circ}$, inciso IX e X do Decreto Federal n ${ }^{\circ}$. 8.124/2013, para apresentar as definições de museu e de processo museológico:

[...] - museu - instituição sem fins lucrativos, de natureza cultural, que conserva, investiga, comunica, interpreta e expõe, para fins de preservação, estudo, pesquisa, educação, contemplação e turismo, conjuntos e coleções de valor histórico, artístico, científico, técnico ou de outra natureza cultural, abertos ao público, a serviço da sociedade e de seu desenvolvimento; - processo museológico - programa, projeto e ação em desenvolvimento ou desenvolvido com fundamentos teórico e prático da museologia, que considere o território, o patrimônio cultural e a memória social de comunidades específicas, para produzir conhecimento e desenvolvimento cultural e socioeconômico. (BRASIL, 2017, p. s/p).

Segundo a definição do ICOM e da Portaria $n^{\circ}$. 422/2017, o museu e o processo museológico possuem a função de conservar e educar para o patrimônio cultural, e tornar esses espaços acessíveis aos cidadãos.

Segundo o National Research Council (2009), Marandino (2001) e Seiffert-Santos e Cunha (2018b), os Museus de Ciências são visitados principalmente por escolas, e são considerados como modalidade de Divulgação Científica. Contudo, conforme as definições apresentadas os museus são sem fins lucrativos e possuem um projeto de educação próprio, o que os distingue de outras modalidades de DC, como as revistas de editoras privadas, que possuem objetivos mercadológicos e não se pautam necessariamente a um projeto educativo explícito.

Nossa proposta é considerar cada um desses meios ou cada uma dessas instituições Escola, Divulgação Científica e Museus de Ciências - como esferas relativamente autônomas da cultura humana ${ }^{6}$. Por eles perpassam, no entanto, redes de relações que contribuem para a formação cidadã. No que concerne a essa ideia, apresentamos, na Figura 1, uma proposta de possibilidade de quatro relações de interações de esferas, ou seja, construções sociais e culturais que se integram relacionalmente em esferas de atividades ${ }^{7}$ (GRILLO, 2013).

\footnotetext{
${ }^{6}$ Evitamos, por enquanto, termos como "educação" ou "aprendizagem" ligados a expressões como "formal”, "não formal" e "informal", isso por entendermos essa nomenclatura como não eficaz para o nosso problema de diálogo, embora saibamos que é uma linguagem bastante utilizada em trabalhos luso-brasileiros, em especial o epíteto específico "não formal".

${ }^{7}$ Esfera da atividade humana, ou esfera ideológica, é um conceito proveniente do círculo de Bakhtin no qual, por meio da teoria enunciativa do discurso ideológico, determinada ideologia é desenvolvida por grupo de indivíduos (sociocultural) que possuem atividade material situada no tempo e espaço, e assim, constroem um discurso de sentido próprio com estilo e composição que refratam essas condições de dialogismo material, histórico e social. O conceito de esfera da atividade humana se assemelha ao conceito de campo de Bourdieu no qual há disputas e
} 


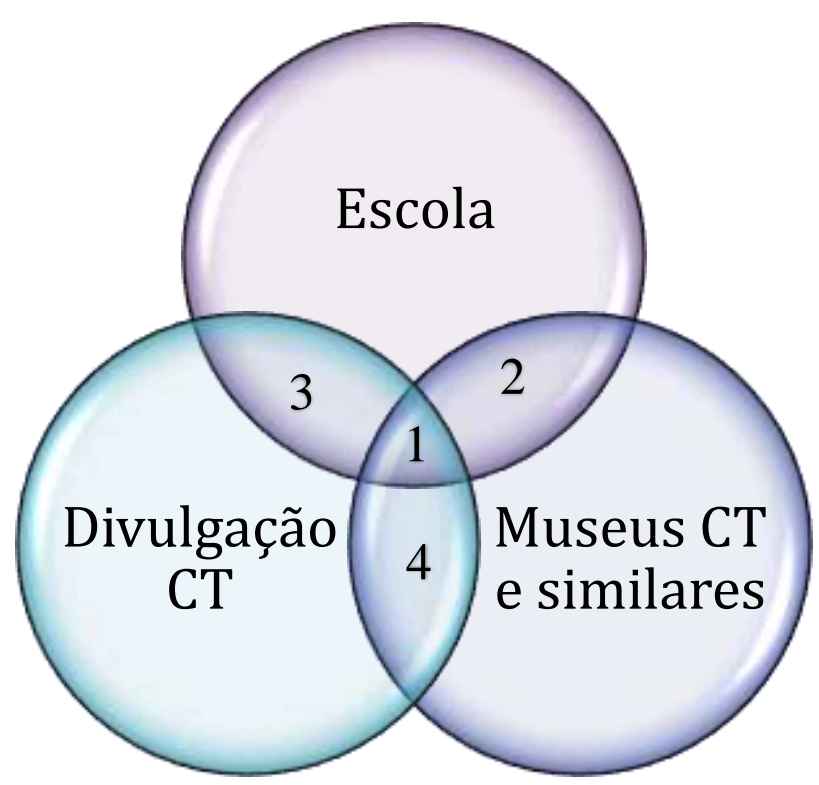

Figura 1 - Esferas de ação humana associadas à difusão da Ciência e Tecnologia. Fonte: Do autor.

A relação de número 1, envolvendo as três esferas, conforma o uso da escola, do espaço do museu ou espaço de educação não formal e propostas em função da DC. É a relação mais completa. Nesse caso conforma o encontro dos trabalhos de uso de Espaços de Educação Não Formal (museu de Ciências) pela escola, ou seja, a escola recebe ou interage com a proposta de educação museal.

A relação 1 normalmente investiga o desenvolvimento do letramento científico por meio da aprendizagem, como pode ser verificado nas pesquisas de Gerber, Cavallo e Marek (2001), Marandino (2001), Seiffert-Santos e Fachín-Terán (2013), Cascais e Fachín-Terán (2015) e Lin e Schunn (2016). Outras pesquisas buscam compreender a potencialidade educativa ou comunicacional da exposição, a exemplo de Hooper-Greenhill (1999) e Seiffert-Santos e Cunha (2018), e algumas vezes a investigação se dá por meio de material de apoio como roteiros ou no discurso do mediador/monitor, como em Rocha e Fachín-Terán (2010), Guisasola et al. (2009) e Bizerra e Marandino, (2011).

A relação de número 2 consiste na interseção de áreas da escola e do museu de Ciências e similares, sem a função necessária de divulgar a Ciência, e à qual podem ser associadas as 
atividades de lazer/desporto, ou de aula de campo, em que não há ação do monitor, mas um roteiro escolar para atividade avaliativa do professor ou da escola.

Na relação 2, as pesquisas enfatizam a percepção da audiência e a perspectiva estética e lúdica, a exemplo de Hooper-Greenhill (1999), Moraes e Amaral (2015) e Santos e Ferreira (2017), em especial com atividades com crianças, conforme Cheng et al. (2011), Mululo e Fachín-Terán (2016) e Chaves et al. (2016).

A penúltima relação, a de número 3, se dá na interação da escola com a DC sem ser atividade em museu de Ciências. Trata-se de uma interação em que a escola se utiliza de alguma mídia de DC, a exemplo de revistas (impressas ou digitais), blogues sobre o tema, livros, programas em canais de comunicação de massa ou em canais da internet. Aqui pode haver associação com uso de espaços diversos (sem ser necessariamente o museu de Ciências), como praças, feiras e locais comunitários, ou com abertura popular livre, todavia contando com o uso de pesquisa de mídia de divulgação científica como desdobramento da pesquisa escolar.

Na relação 3, as investigações apresentam um foco nas mídias científicas com base na análise de conteúdo e na análise discursiva de textos, a exemplo de Cunha $(2008,2019)$ e Seiffert-Santos e Cunha (2018b). Há a possibilidade de uso de pesquisa de materiais de divulgação científica para a visita a ambientes abertos, não necessariamente de ECT, como feiras, praças e lugares abertos, o que é identificado, no contexto brasileiro, como "espaço não formal não institucional” (JACOBUCCI, 2008; ROCHA; FACHÍN-TERÁN, 2010) e como "aprendizagem informal" (informal learning) no contexto internacional (NRC, 2009; STOCKLMAYER et al., 2010). Mesmo assim, o desenho da atividade é o primado do uso de material de DC em espaço não formal.

A última relação visualizada na figura, a de número 4 , indica uma interação entre as mídias de DC com as visitas programadas a museus de Ciências. Essa perspectiva pode ser entendida como a proposta da educação museal propriamente dita e o seu dialogismo com outras mídias na problematização dos temas de Ciência e Tecnologia na diversidade de audiências. Nessa relação, se trata das pesquisas de percepção pública da Ciência, estratégias interpretativas de audiências, aprendizagem informal e investigações sobre a instituição museal, mediadores e respectivas produções, o que pode ser visto em Hooper-Greenhill (1999), NRC (2009), Gruzman (2012), e Cordeiro e Tomio (2017).

Esse esquema não é exclusivo da Figura 1, mas de ilustração das relações predominantes no caso do enfoque nas interações. A não exclusividade se justifica, por exemplo, entre outras 
possibilidades, na relação 4, na qual não necessariamente temos como audiência os escolares, mas os familiares, os amigos do bairro, ou membros de associações civis (grupo de idosos, mães, religiosos, de sindicalistas etc.).

É importante ressaltar que a DC é uma ação do campo comunicativo abrangente e não fechado a um único setor da sociedade, praticado seja por cientistas, seja por curiosos no assunto. É por isso que a educação não formal realizada pelos Museus de Ciências e espaços similares se ancora na divulgação no sentido amplo, todavia com a sua especificidade institucional baseada na pesquisa, na conservação e na divulgação do patrimônio cultural e, no caso do museu de Ciências, no processo de musealização de artefatos e exposições baseadas em objetos ou conceitos científicos (MARANDINO, 2011).

Assim, a DC envolve atividades que têm como objetivo informar o desenvolvimento da Ciência e da Tecnologia e da percepção pública a respeito dessa área do conhecimento, enquanto o conceito estadunidense de scientific literacy, ou seja, de letramento científico, se baseou inicialmente na teoria do deficit. Segundo essa teoria, ao ser exposto à informação, o cidadão é capaz de compreender a Ciência e a Tecnologia, ou seja, o cidadão é um leigo que recebe o saber dos "letrados cientificamente" (VOGT; CERQUEIRA; KANASHIRO, 2018).

Por outro lado, podemos dizer que, nas últimas décadas, a teoria do deficit tem sido descreditada devido à visão cultural de que o cidadão é capaz de dialogar e construir o seu conhecimento socialmente e, portanto, o conhecimento não lhe é imposto e tampouco o cidadão é tratado como incapaz. Nesse mesmo sentido, no Reino Unido (especificamente na Inglaterra) é utilizada a expressão popularization understanding of Science, ou seja, compreensão pública da Ciência, ou a percepção pública da Ciência em termos de conceitos e de teorias científicas. Esse conceito se alinha a uma compreensão de que a Ciência e a Tecnologia são produções humanas mutáveis e desenvolvidas na sociedade, valendo dizer que são frutos da produção cultural humana e, por isso, são próprias do que se designaria de cultura científica (VOGT; CERQUEIRA; KANASHIRO, 2018).

Nessa rede de relações, o museu é alvo dessas pesquisas, seja enquanto percepção pública da Ciência seja enquanto aprendizagem informal ou não formal, isto é, aprendizagem museal, divulgação científica e espaço de atividades para os escolares. Nesse sentido, as pesquisas podem ser baseadas i) em audiência e/ou em grupo de monitores/mediadores e/ou ii) em exposições (HOOPER-GREENHILL, 1999; MARANDINO, 2011; GRUZMAN, 2012). 
Nesse esquema de relações entre a escola, a DC e o museu (ou educação não formal), a região Norte brasileira tem realizado diversas pesquisas. Todavia tem ocorrido, do nosso ponto de vista na região Norte predominantemente, mas também em outras pesquisas nacionais, uma maior concentração na relação 3 , ou seja, a que prima pelo uso modificado de mídias da DC para a aprendizagem de ciências e pela oportunidade de lazer dos escolares no espaço não formal (SEIFFERT-SANTOS; FACHÍN-TERÁN, 2013; SEIFFERT-SANTOS, 2016b). Por esse ângulo, em função da região possuir poucos museus, embora haja vários congêneres de museus, a pesquisa de potencialidade educativa tem apresentado uma forma de caracterização dos espaços, ou descrições, deixando de adotar teorias e dados investigativos fundamentados no campo da educação museal e da educação não formal, no qual se apoia o processo educativo da instituição em Ciência e Tecnologia (SEIFFERT-SANTOS; CUNHA, 2019).

Uma explicação possível, segundo Seiffert-Santos e Cunha (2018b), é que a região não foi contemplada nos editais do governo federal para formação de grupos de estudo, pesquisa e desenvolvimento em educação em ciências e museus de ciências nas décadas de 1960 e 1970. Registramos fomento de novas linhas de pesquisas sobre o uso de espaços não formais a partir da década de 2010, com os programas de pós-graduação em mestrado em educação em ciências (SEIFFERT-SANTOS; FACHÍN-TERÁN, 2013).

Como destacamos, nas relações 1, 3 e 4 o museu é observado como instituição, com identidade, cultura institucional e estratégias próprias, voltadas para os seus objetivos, entre outros o de receber escolares. Entretanto, uma pesquisa na relação 4 tende a contribuir para a compreensão institucional, bem como para os arranjos voltadas às pesquisas da relação escola/museu.

Em outras palavras, as pesquisas com o olhar da escola para museu não substituem a contribuição do olhar do museu e seus processos de educação não formal para a escola. Ambas têm muito a contribuir uma para a outra no processo de formação crítica do cidadão, dentro das suas esferas e realidades. Nesse âmbito destacamos o trabalho de Marandino (2001), que buscou tecer entendimentos para além das descrições do espaço não formal museal, por meio da teoria da transposição didática e, também, por meio da teoria do dispositivo e discurso pedagógico de Bernstein, do discurso bioexpositivo, ou seja, do discurso científico transformado no discurso da exposição museal de temas biológicos de museus universitários, não se centrando somente no discurso do monitor em relação à aprendizagem. Depois de Marandino, na mesma área temática, agora designada de "discurso expositivo", Gruzman (2012) desenvolveu análises a 
partir da teoria enunciativa de Bakhtin. A partir desses parâmetros, a pesquisadora compôs uma compreensão ideológica por meio do dialogismo ${ }^{8}$ e dos conceitos de autoria e de esfera de atividade. Gruzman (2012) apresentou uma intencionalidade discursiva das exposições, influenciada pela circulação de sentido pelas esferas de atividades associadas ao museu.

A compreensão da intencionalidade do discurso expositivo é duplamente importante para o processo de educação não formal dialógica e também para a educação formal apoiada na relação 2 (Escola e Museu de Ciências). Acreditamos que o presente diálogo tende a contribuir para uma construção e para a articulação dessas relações veiculadas em exposições de Ciência em espaços de educação não formal.

\section{CONTRIBUIÇÕES DA INTERAÇÃO DA RELAÇÃO 2 - ESCOLA/MUSEU}

Defendemos que a divulgação científica se dá por meio de relações de construção de sentido na circulação das esferas da atividade humana, no qual se destacam a Escola e o Museu de Ciências por seus projetos educativos, e suas interações dialógicas podem ser valoradas de forma positiva elou negativa para possibilitar uma formação dialógica ou monológica dos públicos. Vemos a possibilidade da relação integrativa 2 com elementos da relação 1, o que pode tornar a relação mais completa dialogicamente. Todavia, há posições que tornam isso possível e outras não. Ressaltamos que esse exemplo ilustrativo de análise de uma única relação pode ser expandido para as outras relações. Contudo, considerado o espaço disponível vamos nos delimitar na relação mais importante, por se tratar da Escola e do Museu de Ciências.

A relação foca nas atividades de lazer/desporto, ou de aula de campo, em que não há ação do monitor, mas um roteiro escolar para atividade avaliativa do professor ou da escola. Desta forma a relação se dá pela interação do Museu de Ciências (ou o seu similar, como o Parque Temático Bosque da Ciência/INPA ${ }^{9}$ ) e a Escola, na condição de dialogismo de esferas

\footnotetext{
${ }^{8}$ Segundo Fiori (2016, p. 22) o dialogismo em Bakhtin "são relações de sentido que se estabelecem entre dois enunciados", visível na (a) interação verbal, (b) vozes presentes no enunciado (discurso direto, indireto e indireto livre), e (c) na relação social com o outro.

${ }^{9}$ Os artigos que consultamos sobre pesquisas no Bosque da Ciência foram os de Seiffert-Santos (2016b) e o Seiffert-Santos e Cunha (2018). O primeiro levantou 51 textos publicados entre o período de 2010 a 2015 sobre espaços não formais e escola, entre resumos e textos completos de anais de evento, capítulos de livros e artigo em revistas, contudo alguns trabalhos se relacionam ao Bosque da Ciência. O segundo investigou 24 textos completos publicados em anais de eventos e revistas científicas entre 2010 a 2018 sobre o Bosque da Ciência.
} 
distintas, instituições com missões diferentes, com pontos de aproximação e outros de afastamento.

Podemos sintetizar essa interação na seguinte relação estrutural:

$$
\text { Escola }+/-<>\quad-/+ \text { Bosque da Ciência }
$$

\begin{tabular}{|l|c|l|l|}
\hline Esfera Educativa & Interações & Esfera Museal & Dialogismo \\
\hline Escola & $+>-$ & Museu & Formalismo escolar \\
\hline Escola & $->+$ & Museu & Formalismo museal \\
\hline Escola & $->-$ & Museu & Isolamento cultural \\
\hline Escola & $+>+$ & Museu & Diálogo cultural \\
\hline
\end{tabular}

Quadro 1 - Relação de interação entre escola e museu.

Fonte: Do autor.

A partir do Quadro 1 podemos perceber algumas formas possíveis de interação entre escola e museu de Ciências. Através dessas interações podemos dialogar com as formas de pensar a educação formal (escolar) em dialogismo com a educação não formal (museal).

A interação de valorização da escola em detrimento do museu gera um formalismo escolar, vê na escolarização como a orientação organizadora cultural da relação do sujeito com a educação não formal (museu). Assim, podemos ver dialogicamente a possibilidade de duas perspectivas: a) assimilação do museu pela escola, ou seja, o museu é lido por lentes escolares, e aquilo que não convêm ao olhar escolarizado é ignorado ou descontextualizado do ambiente proposto, do ambiente museal e do sentido no qual foi intencionado; b) conflito de negação da importância ou relevância da interação com o museu, isto é, a escola nega as contribuições do museu para a formação educativa dos alunos, e dessa forma não agenda visitas e nem orienta atividades em conjunto com essas instituições.

No trabalho de Seiffert-Santos (2016b) são listados poucos trabalhos que impõem totalmente a visão do conteúdo escolar de tal forma que é dispensado o monitor. A assimilação pode ser feita em atividades de aulas práticas de cursos técnicos ou superiores que são guiadas por professores das escolas. A outra perspectiva, a visão do que chamamos de formalismo escolar, somente pode ser verificada de forma indireta, considerada a dificuldade em se perceber que alguma escola não agenda visitas aos espaços não formais.

Exemplificamos parcialmente com o texto de Mota, Jesus e Fachín-Terán (2013) no qual são construídas três propostas de aulas para o Ensino Fundamental voltadas para alguns conceitos de Matemática e de Química na atividade de uma disciplina do mestrado acadêmico em Educação em Ciências, e nelas a sugestão é que o espaço a ser utilizado seja o Bosque da Ciência, no qual alguns objetos de exposição são tomados como elementos de análise 
disciplinar, a saber: alguns conceitos de geometria plana empregados na folha de Coccoloba, o raio e diâmetro da espécie botânica tanimbuca (Buchenavea huberi Ducke), e aspectos físicos e pH das águas do Lago Amazônico e espelho d'água da ilha da Tanimbuca. A atividade nos parece um exercício de aproximação reflexiva dos elementos do Bosque junto aos professores em relação aos conceitos que trabalham nas suas disciplinas na Educação Básica. Não é referendado o acompanhamento de monitor, uso da história e do contexto ambiental. Apesar de inevitável o uso desses elementos devido ao próprio ambiente, eles concluem como ambiente viável para atividade escolar. Assim, o Bosque da Ciência na condição de ECT e espaço de educação não formal é assimilado. Da nossa forma de ver, isso não é necessariamente negativo, porém torna-se reduzido se considerarmos as possibilidades interdisciplinares ou transdisciplinares com a oportunidade de dialogar com tantos elementos presentes de natureza relacional, social e biológica.

A interação de valorização do museu/educação não formal sem considerar as necessidades do público escolar concebe um formalismo museal, vê na educação não formal como a orientação organizadora cultural da relação do sujeito com a educação formal (escola). Também há duas formas de orientação dialógica: a) assimilação dos escolares como visitantes ou público geral, ou seja, nada havendo de diferente que dialogue com temática ou disciplina escolar de forma planejada ou extrínseca, a atividade torna-se uma ação de enriquecimento cultural; b) assimilação da comunidade como atividade de educação não formal, isto é, comunidades com identidade sociocultural própria formam sua educação a partir do seu contexto sociocultural.

A perspectiva de assimilação dos escolares como visitantes em geral é visto em Higuchi e Farias (2002) no projeto Pequenos Guias em educação ambiental desenvolvido pelo Laboratório de Psicologia e Educação Ambiental do INPA, finalizado em 2010, no Bosque da Ciência. As crianças eram selecionadas, estudavam e viviam o espaço de educação não formal e participavam das atividades socioeducativas em educação ambiental, e depois realizavam a atividade de guia aos visitantes e assim traziam um enriquecimento cultural, que embora não fosse aprofundado era o suficiente para conhecer as exposições e atrativos. Todavia, não havia diferença visível entre os conteúdos e abordagens para visitante em geral e visita escolar.

Outra forma dessa perspectiva está apresentada nos trabalhos da pesquisadora Maria da Glória Gohn (2011), que trabalhou com assentamentos da reforma agrária e emancipação política desses, e assim, a educação não formal comunitária é ao mesmo tempo atividade 
política, material e social, integrando e assimilando num projeto de comunidade e práxis social. Nesse exemplo mostra-se a complexidade da temática e da realidade, pois no contexto de assentamento a escola torna-se atividade submissa à realidade local, e não o contrário.

A interação do isolamento cultural pode não ser admitida, mas sua ocorrência é percebida tacitamente. É o isolamento da instituição cultural em si mesma, sem diálogo com as instituições de educação não formal, e vice-versa, que se desenvolve da seguinte maneira: a escola, de forma radical, se fecha no seu currículo, materiais didáticos e recursos humanos, e não articula atividades de intercâmbio, visitas aos museus e nem tão pouco com mídias físicas e virtuais fora ao material curricular oficial, ou seja, é um fechamento cultural para a visão de mundo dos estudantes. Situação semelhante também é verificada em instituições de educação não formal que se isolam e não buscam parcerias com outras instituições e com escolas para apresentar seus produtos e acervos, bem como para fazer interação com os seus profissionais. O final dedutivo é o definhamento e o fechamento de tal instituição pelo reducionismo formativo com o seu quadro interno e com a sua audiência/público (CURY, 2005).

E por fim, na interação do diálogo cultural, ambas as instituições propõem parcerias delimitadas, sem assimilações da função alheia, no qual o diálogo pode ser o parâmetro de integração, em especial nos pontos convergentes de suas missões e atividades, respeitando os pontos de tensões a respeito da sua integridade institucional. Atividades aqui podem ser a escola com espaços abertos para inclusão de propostas museais e/ou museus com propostas afins para grupos e interesses básicos de escolares (ou programas específicos se for possível). Nesse sentido, a relação 2 torna-se a relação 1, integração da proposta escolar e educação não formal como formas de aproximar da cultura científica.

Nessa última interação há uma forma interinstitucional de tratamento, ou seja, uma forma intercultural, pois o conhecimento institucionalizado é oferecido de outra forma, havendo uma interdisciplinaridade da disciplina escolar junto à disciplina museal. Para ilustrar, o trabalho de Menezes, Fachín-Terán e Vogt (2018) realiza uma pesquisa entre o Centro de Estudo e Pesquisa de Quelônios da Amazônia (CEQUA), laboratório presente no Bosque, com alunos do $7^{\circ}$ ano do Ensino Fundamental, em conteúdo próprio desse nível escolar (os seres vivos), com atividades de exposição de animais vivos e outros elementos biológicos e avaliação por questionário. A interação foi composta para além dos assuntos biológicos, relacionando-se com a educação ambiental. Verificamos nesse caso um dialogismo entre o currículo escolar e o projeto de educação museal devidamente planejado e executado. 
Segundo Seiffert-Santos (2016b) entre 51 trabalhos com espaços não formais em Manaus envolvendo o ensino de ciências, a maioria deles apresentando o Bosque da Ciência como espaço não formal, em 12 trabalhos foram observadas abordagens interdisciplinares. De certa forma, confirmada a existência do diálogo entre a escola e a educação não formal em ECT, valida-se a necessidade de interação para além da Ciência, com outras formas de conhecimento e de construção didática alternativa, em função do contexto promovido pelo espaço diferenciado de educação não formal, ou seja, ambientes naturais com recursos vivos e normalmente abertos, abrindo uma visão rica para além da sala de aula.

\section{CONSIDERAÇÕES}

Vimos conforme o nosso objetivo que a Escola, a Divulgação Científica e o Museu de Ciências interagem como esferas de atividade humana e, mesmo com sua relativa autonomia, as suas interações são fonte de enriquecimento cultural mútuo. Dessa forma, a relação entre Escola/Museu de Ciência (ou Escola/Educação não formal), esta relação entendida no contexto amazônico, para ser mais específico, no estado do Amazonas, rico em instituições similares ao Museu de Ciências, como zoológicos, jardins botânicos e parques temáticos, ou seja, espaços de educação não formal abertos e abundante em elementos naturais e vivos. A interação positiva entre escola/museu de ciências contribui para a abertura da visão da diversidade cultural, social e biótica.

A relação de número 2 - escola e museu de ciências -, associada à nossa tese, indicou por meio da nossa análise que as interações positivas e negativas um desdobramento baseado no tipo de dialogismo possível, no qual podem abrir ou fechar culturalmente o enriquecimento das suas audiências/públicos. Mas se o desdobramento for aberto, em diálogo, as instituições podem contribuir para atividades interdisciplinares e interculturais, numa superação da relação de tipo 2 (lazer ou aula prática ministrada pelo professor, mas sem interação com monitores) pela relação de tipo 1, na qual não basta o uso do espaço não formal, mas o encontro de propostas de educação, a escola e o museu de Ciências. É um encontro de missões, objetivos, propostas e profissionais pensando a melhor forma de promover a cultura científica para a formação de cidadãos, e não somente de conteúdos disciplinares.

Dessa forma a visão escolar contribui para a construção de atividades para os Museus de Ciências, como o Bosque da Ciência. Também a visão institucional do Museu deve ser 
levada em consideração na Escola, como respeito e enriquecimento de uma visão institucional diferente e consistente com a realidade e as demandas sociais do seu tempo.

\section{REFERÊNCIAS}

ABCMC - ASSOCIAÇÃO BRASILEIRA DE CENTROS E MUSEUS DE CIÊNCIA. Centros e museus de Ciência do Brasil 2015. Rio de Janeiro: ABCMC: UFRJ.FCC. CC; Fiocruz. Museu da Vida, 2015.

BIZERRA, A.; MARANDINO, M. Formação de mediadores museais: contribuições da Teoria da Atividade. In: $8^{\mathbf{0}}$ Encontro Nacional de Pesquisadores em Educação em Ciências. Anais do ENPEC - Encontro Nacional de Pesquisadores em Educação em Ciências. Águas de Lindoia: ABRAPEC, 2011.

BRASIL. Instituto Brasileiro de Museus. Portaria ${ }^{\circ}$ 422, de 30 de novembro de 2017 Dispõe sobre a Política Nacional de Educação Museal - PNEM e dá outras providências. Diário Oficial da União, p. 12-14, 2017.

BUENO, W. C. José Reis: a divulgação científica como compromisso. Comunicação \& Sociedade, São Paulo. v. 24, n. 38, p. 227-235, 2002.

CAMPUS, M. Manual de Redação Científica: ensaio acadêmico, relatório de experimento e artigo científico. [s.l:s.n], 2015. Disponível: https://br.pinterest.com/pin/167688786105299228/ Acessado em 22 ago. 2020.

CASCAIS, M. G. A.; FACHÍN-TERÁN, A. Os espaços educativos e a alfabetização científica no Ensino Fundamental. Manaus: Editora \& Gráfica Moderna, 2015.

CAZELLI, S.; VALENTE, M. E. Incursões sobre os termos e conceitos da educação museal. Revista Docência e Cibercultura, Rio de Janeiro. v. 3, n. 2, p. 18-40, 1 set. 2019.

CEnTRO de Gestão e estudos estratéGiCOS. Percepção Pública da Ciência \& Tecnologia no Brasil-2019. Resumo executivo. [s.l: s.n.], 2019. Disponível: http://www.cgee.org.br Acessado em 01 out. 2019.

CHAGAS, I. Aprendizagem Não Formal/Formal das Ciências: relações entre os museus de ciência e as escolas. Revista de Educação, Lisboa. v. 3, n. 1993, p. 51-59, 1993.

CHAVES, R. et al. Educação infantil e os espaços não formais: uma perspectiva de aprendizagem no Parque Municipal Germano Augusto Sampaio em Boa Vista/RR. Areté Revista Amazônica de Ensino de Ciências, Manaus. v. 9, n. 20, p. 89-97, 9 maio 2016.

CHENG, M.; ANNETTA, L.; FOLTA, E.; HOLMES, S. Y. Drugs and the Brain: Learning the impact of methamphetamine abuse on the brain through a virtual brain exhibit in the museum. International Journal of Science Education, [S.1]. v. 33, n. 2, p. 299-319, 15 jan. 2011. 
CORDEIRO, M. L.; TOMIO, D. O Museu de Ecologia Fritz Müller: Tessituras para Educação Científica e a Pesquisa. Alexandria - Revista de Educação em Ciência e Tecnologia, Florianópolis. v. 10, n. 1, p. 169-198, 2017.

COSTA, R. A. Política Cultural e Museus no Amazonas (1997-2010). 2011. $164 \mathrm{f}$. Dissertação (Mestrado). Programa de Pós-Graduação em Sociologia, Instituto de Ciências Humanas e Letras. Universidade Federal do Amazonas. UFAM: Manaus, 2011.

CUNHA, M. B. Concepções de Ciência no jornalismo: uma análise da divulgação científica em jornais. In: $2^{\circ}$ Simpósio Internacional de Análise Crítica do Discurso; Encontro Nacional de Interação e Linguagem Verbal Não Verbal. São Paulo. Anais do $2^{\circ}$ Simpósio Internacional de Análise Crítica do Discurso. São Paulo: USP, 2008.

CUNHA, M. B. Divulgação científica: Diálogos com o Ensino de Ciências. Curitiba: Appris, 2019.

CUNHA, R. B. Alfabetização científica ou letramento científico?: interesses envolvidos nas interpretações da noção de scientific literacy. Revista Brasileira de Educação, Rio de Janeiro, v. 22, n. 68, p. 169-186, mar. 2017.

CURY, M. X. Comunicação e pesquisa de recepção: uma perspectiva teórico-metodológica para os museus. História, Ciências, Saúde - Manguinhos, Rio de Janeiro. v. 12, p. 365-380, 2005.

ESHACH, H. Bridging In-school and Out-of-school Learning: Formal, Non-Formal, and Informal Education. Journal of Science Education and Technology, [S.1]. v. 16, n. 2, p. 171-190, 18 maio 2007.

FERRI, C. (Org.). Produção acadêmico-científica [recurso eletrônico]: a pesquisa e o ensaio. Universidade do Vale do Itajaí. Itajaí: Universidade do Vale do Itajaí, 2011. Disponível em: encurtador.com.br/fxSX1 Acessado em 22 ago. 2020.

FIORIN, J. L. Introdução ao pensamento de Bakhtin. 2. ed. São Paulo: Contexto, 2016. FONSECA, O. M. Pensando a Amazônia. Manaus: Editora Valer, 2011.

GERBER, B.; CAVALLO, A.; MAREK, E. Relationships among informal learning environments, teaching procedures and scientific reasoning ability. International Journal of Science Education, [S.1.]. v. 23, n. 5, p. 535-549, 2001.

GOHN, M. G. Educação não formal e cultura política. 5. ed. São Paulo: Ed. Cortez, 2011.

GRILLO, S. V. C. Divulgação científica: linguagens, esferas e gêneros. 2013. 333f. Tese (Doutorado). Departamento de Letras Clássicas e Vernáculas. Faculdade de Filosofia, Letras e Ciências Humanas. Universidade de São Paulo. São Paulo, 2013.

GRUZMAN, C. Educação, ciência e saúde no museu: uma análise enunciativo-discursiva da exposição do Museu de Microbiologia do Instituto Butantan. 2012. 280f. Tese (Doutorado). Faculdade de Educação, Universidade de São Paulo. São Paulo, 2012. 
GUISASOLA, J.; SOLBES, J.; BARRAGUES, J.; MORENTIN, M.; MORENO, A. Students' Understanding of the Special Theory of Relativity and Design for a Guided Visit to a Science Museum. International Journal of Science Education, [S.1]. v. 31, n. 15, p. 2085-2104, out. 2009.

HIGUCHI, M. I. G.; FARIAS, M. S. M. de. Pequenos guias do Bosque da Ciência: trajetória de experiência de educação ambiental com crianças na Amazônia. Manaus: INPA, 2002.

HOOPER-GREENHILL, E. Learning in art museums: strategies of interpretation. In: The educational role of the museum. [s.1: s.n.], 1999. p. 44-52.

JACOBUCCI, D. F. C. Contribuição dos espaços não-formais de educação para a formação da cultura científica. Revista Em Extensão, Uberlândia. v. 7, p. 57-66, 2008.

LIN, PEI-YI; SCHUNN, C. D. The dimensions and impact of informal science learning experiences on middle schoolers' attitudes and abilities in science, International Journal of Science Education, [S.1]. v. 38, n. 17, p. 2551-2572, 2016. DOI: 10.1080/09500693.2016.1251631 Acessado em 01 abr 2018.

MARANDINO, M. O conhecimento biológico nas exposições de museus de ciências: análise do processo de construção do discurso expositivo. 2001. 450f. SP: Tese (Doutorado). Faculdade de Educação, Universidade de São Paulo, São Paulo, 2001.

MARANDINO, M. Por uma didática museal: propondo bases sociológicas e epistemológicas para análise da educação em museus. 2011. Tese (Livre Docente). Faculdade de Educação, Universidade de São Paulo. São Paulo, 2011.

MARANDINO, M. Faz sentido ainda propor a separação entre os termos educação formal, não formal e informal? Ciênc. educ., Bauru, v. 23, n. 4, p. 811-816, Dec. 2017.

MATTOS, P. C. Tipos de revisão da literatura. Botucatu: [s.n], 2015. Disponível em: https://docplayer.com.br/12500538-Tipos-de-revisao-de-literatura.html Acessado: 22 ago. 2020.

MENEGHETTI, F. K. O que é um ensaio-teórico? RAC, Curitiba, v. 15, n. 2, p. 320-332, Apr. 2011. Disponível em http://www.scielo.br/scielo.php?script=sci_arttext\&pid=S1415-

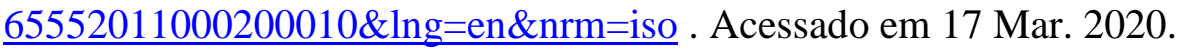

MENEZES, S. B.; FACHÍN-TERÁN, A.; VOGT, R. C. Alfabetização científica usando o tema dos quelônios amazônicos. ReBECEM, Cascavel, (PR), v. 2, n. 1, p. 92-105, abr. 2018.

MORAES, V. S.; AMARAL, M. B. "Livres para voar": o Museu Nacional do Rio de Janeiro nas imagens e palavras de uma professora e seus alunos do Ensino Médio. Alexandria Revista de Educação em Ciência e Tecnologia, [S.1.]. v. 8, n. 2, p. 33-51, 2015.

MOTA, D. M.; JESUS, R. L.; FACHÍN-TERÁN, A. Possibilidades de ensino de Matemática e Química no espaço não formal: Bosque da Ciência. In: Conferência da Associação 


\section{REAMEC

Latinoamericana de Investigação em Educação em Ciências. Anais da Conferência da Associação Latinoamericana de Investigação em Educação em Ciências. Manaus, AM, Brasil, 22 a 25 de outubro de 2013.

MULULO, J. C. P.; FACHÍN-TERÁN, A. Indagações dos estudantes durante as aulas passeio no Bosque da Ciência, Manaus, AM. In: FACHÍN-TERÁN, A.; SEIFFERT-SANTOS, S. C. Temas sobre ensino de ciências em espaços não formais: avanços e perspectiva. Manaus: UEA Edições, 2016. p. 165-180.

NASCIMENTO, S. S. A relação museu e escola na prática docente: tensões de uma atividade educativa. In: DALBEN. A.; DINIZ, J.; LEAL, L.; SANTOS, L. (Orgs.). Convergências e tensões no campo da formação e do trabalho docente. Belo Horizonte: Autêntica, 2010, p. $357-369$.

NRC - NATIONAL RESEARCH COUNCIL. Learning Science in Informal

Environments: People, Places, and Pursuits. In: BELL, P.; LEWENSTEIN, B; SHOUSE, A. W.; FEDER, M. A. (Eds.). Washington DC: The Nacional Academies Press, 2009.

OVIGLI, D. Panorama das pesquisas brasileiras sobre educação em museus. Revista Brasileira de Estudos Pedagógicos, Brasília, v. 96, p. 577-595, 2015.

PALHARES, J. A. Reflexões sobre o não-escolar na escola e para além dela. Revista Portuguesa de Educação, Braga. v. 22, p. 53-84, 2009.

ROCHA, S. C. B.; FACHÍN-TERÁN, A. O uso de espaços não formais como estratégia para o ensino de ciências. Manaus: UEA/PPGEECA, 2010.

SANTOS, L. R.; FERREIRA, F. H. N. O uso de recursos didáticos como estratégia educacional em espaços formais e não formais de educação. Areté - Revista Amazônica de Ensino de Ciências, Manaus, v. 10, n. 22, p. 11-22, 5 jul. 2017.

SEIFFERT-SANTOS, S. C.; CUNHA, M. B. A pesquisa em espaços de educação não formal em Ciências na Região Norte: o caso do Bosque da Ciência. Amazônia RECM, Belém. v. 14, n. 32, p. 160-173, 2018.

SEIFFERT-SANTOS, S. C.; CUNHA, M. B. Aproximação da teoria do gênero discursivo e a perspectiva comunicacional de museus: cronotopo das gerações museais. In: $\mathbf{6}^{\mathbf{0}}$ Simpósio Nacional de Educação; $27^{\mathrm{a}}$ Semana Acadêmica de Pedagogia; $1^{\mathrm{a}}$ Mostra da PósGraduação, Cascavel. Anais do Simpósio Nacional de Educação. Cascavel: Unioeste, $2018 b$.

SEIFFERT-SANTOS, S. C.; FACHÍN-TERÁN, A. O uso da expressão espaços não formais no ensino de Ciências. Areté - Revista Amazônica de Ensino de Ciências, Manaus, v. 6, n. 11, p. 01-15, 2013.

SEIFFERT-SANTOS, S. C. Espaços educativos científicos: formal, não formal e informal. Areté - Revista Amazônica de Ensino de Ciências, Manaus, v. 9, n. 20, p. 98-107, 2016. 
SEIFFERT-SANTOS, S. C. Aproximações dos espaços educativos não formais e a didática. In: $6^{0}$ Simpósio de Educação em Ciências na Amazônia. 2016. Manaus-AM. Anais do SECAM. Manaus-AM: PPGECA, 2016b.

SEIFFERT-SANTOS, S. C.; CUNHA, M. B. A tradição de pesquisa segundo Laudan em educação em espaços não formais num evento de ensino de Ciências. Góndola, Enseñanza y Aprendizaje de las Ciencias, Bogotá. v. 14, n. 1, p. 88-107, 2019.

STOCKLMAYER, S. M.; RENNIE, L. J.; GILBERT, J. K. The roles of the formal and informal sectors in the provision of effective science education. Studies in Science Education, [S.1.]. v. 46, n. 1, p. 1-44, mar. 2010.

VALENTE, M. E.; CAZELLI, S.; ALVES, F. Museus, ciência e educação: novos desafios. História, Ciências, Saúde- Manguinhos, Rio de Janeiro. v. 12 (suplem), p. 183-203, 2005. VOGT, C.; CERQUEIRA, N.; KANASHIRO, M. ComCiência revista eletrônica de jornalismo científico. Campinas, SP: BCCL/ UNICAMP, 2018.

Submetido em: 17 de março de 2020.

Aprovado em: 17 de setembro de 2020. 